\title{
Collaborative Projects in Geometry
}

\author{
José L. Rodríguez, David Crespo and Dolores Jiménez
}

\section{Sierpinski Carpet Project (2014-16)}

We started our workshop showing the largest Sierpinski carpet in the world, built by more than 40,000 children from 400 centers in 39 countries. The small pieces were assembled in the Palace of Mediterranean Games in Almería on May 13, 2016, with the help of 1000 people. All the information related to this project, including activities on fractals, can be found at http://topologia.wordpress.com/ sierpinski-carpet-project.

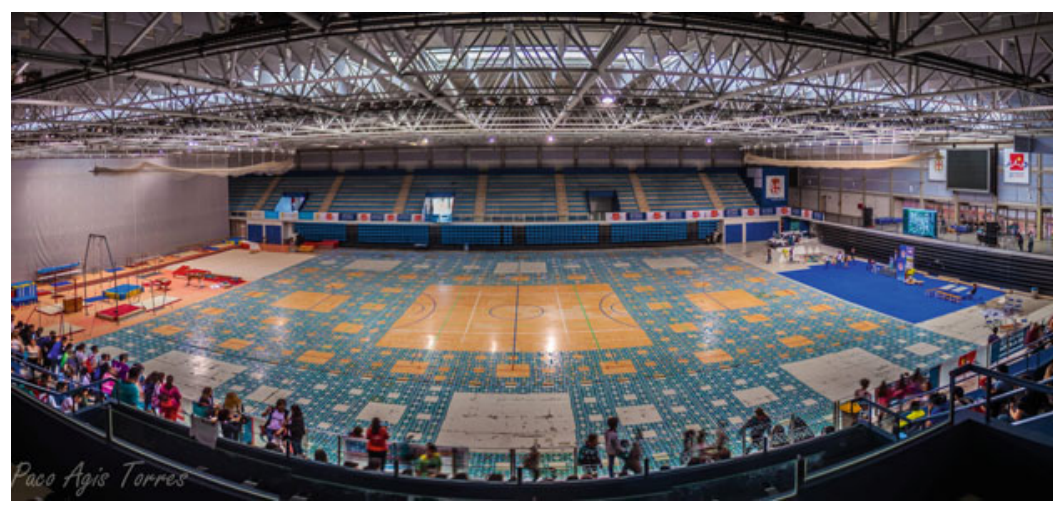

\footnotetext{
J.L. Rodríguez ( $\square)$

Department of Mathematics, University of Almería, Almería, Spain e-mail: jlrodri@ual.es 


\section{Let's Play to Classify Surfaces! (2016-17)}

In the second part of the workshop, we presented a project based on the construction and analysis of surfaces from a topological viewpoint. It was awarded with the First Prize in Mathematics at the Spanish edition of Science on Stage held in Algeciras in October 2016.

Starting with manipulative activities, the project was developed using computational software such as Mathematica or virtual reality (VR).

We spent some time to build several polyhedral surfaces with pieces of our manipulative game, 3D Polyfelt. We then computed their Euler characteristics, among other topological properties.

Materials of this project are available at: https://sites.google.com/a/ual.es/ surfaces.

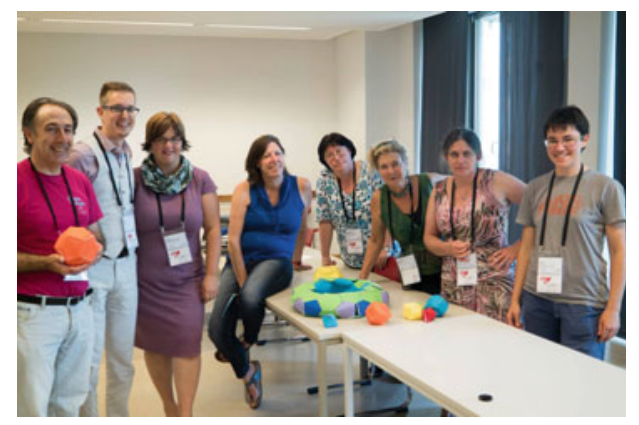

Open Access Except where otherwise noted, this chapter is licensed under a Creative Commons Attribution 4.0 International License. To view a copy of this license, visit http://creativecommons. org/licenses/by/4.0/.

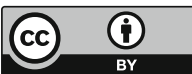

